\title{
Visualization of the thermal environments of RC and composite-wall constructions
}

\author{
H.-Y. Liu \\ Department of Architecture, National Quemoy University, \\ Kinmen, Taiwan
}

\begin{abstract}
In recent years, the promotion of environmental conservation, energy-saving methods and carbon reduction has led to the implementation of a number of new energy codes in many countries to increase building efficiency. The ultimate goal is to create a comfortable and healthier living environment and reduce issues arising from climate-related factors. The aims of this study are to discuss several cost-effective methods that can reduce energy consumption and further improve the thermal environment of buildings in a subtropical country. This research utilizes a portable infrared thermography device to closely inspect and analyze the outdoor and indoor heat-environments of buildings built with reinforced concrete $(\mathrm{RC})$ or of a composite-wall construction through visualization and comparison of thermographic images. By conducting cross-comparison and analysis, various dominant factors in the heat-environment are identified. This paper compares the effect of two different construction methods on the thermal environment and identifies the benefits of using proper materials with a low heat capacity to improve the energy-saving performance. The impacts of the two construction methods on carbon reduction and the heat island effect are also explored. The results of this study can serve as a useful reference and could form the basis of recommendations for building restoration or construction.
\end{abstract}

Keywords: infrared thermography, heat-environment, energy conservation, carbon reduction, thermal images.

\section{Introduction}

The exterior materials, construction method and quality of indoor air are vital characteristics affecting the energy consumption of a building, and control of the 
thermal environment of a building and the characteristics of its exterior envelopes are keys to reducing the energy consumption of a building. In many countries, the authorities have issued technical codes for energy conservation recommending certain designs of building envelopes suitable for the local weather with the aim of reducing energy waste. This is very important in certain continental areas where winter is extremely cold. On the other hand, for countries located in a tropical or sub-tropical climate, the solutions to improve the thermal environment of a building are different. Taiwan is located in the subtropical climate zone, with hot and humid climatic conditions. Increasing urbanization and climate change have raised energy consumption and thermal environment issues correlated to building construction.

The method of construction of the exterior envelope of a building and the choice of construction materials directly affect the heat transfer between the inside and outside of a building. A study by Sun et al. [1] points out that the indoor and outdoor heat flow of a building is caused by heat exchange and ventilation in the exterior walls, ceiling, roof, floors and windows, and complex factors influence the heat flow indoors and outdoors, including the temperature difference, insolation, amount of indoor ventilation, size of open vents, thermal insulation of exterior walls, insolation absorption ratio, and emissivity of exterior surfaces. Therefore, for buildings in extremely hot climates, the effect of insulation and the cooling abilities of the exterior envelopes are determined by their thermal-insulating composition and the nature of the materials used. In addition, a good ventilation system to reduce heat gain and thermal insulation to prevent heat transfer is essential. By installing proper exterior materials with good thermal-insulating properties, the influence of the outdoor heat and the absorption of insolation can be reduced, leading to improvement in the quality of the indoor environment and reduced energy consumption.

In order to study the effects of different construction materials on the thermal environments of buildings, this research utilizes a portable infrared thermography device to inspect the outdoor and indoor environments of buildings through visualization of the heat-environment. By cross-comparison of the indoor and outdoor thermal environment data, the analysis process can identify various key factors affecting the heat-environment. Many conditions influence the accuracy of thermographic measurement (Balaras and Argiriou [2]) give an overview of the use of thermal infrared imaging for the detection of building defects; however, qualified personnel of several different fields with a good understanding of various principles are required to perform accurate measurement. Recently, with further improvement in the technology, analysis and diagnostics of building problems of comparable quality can be performed without the need for human experts in a substantially shorter period of time.

Regarding the impact of buildings on the urban thermal environment, many studies address the most effective designs in terms of energy conservation in countries of cold climatic conditions and calculate the energy consumption; however, very few explore approaches to improve the thermal environment of buildings in subtropical countries. For this purpose, infrared thermography is powerful technique that is particularly suitable for detailed inspection. Haack et 
al. [3] point out that thermal infrared imaging is useful for promptly detecting damaged and humid sites in tunnel construction, and the technique works better than other non-destructive techniques. Sakagami and Kubo [4] develop a method using an infrared thermalgraphic device with a heating system that can identify defects in reinforced concrete (RC) objects. In this study, the critical effects of building materials and construction methods for building renovation under hot and humid climatic conditions are further explored, and the results can be used to form the basis of recommendations for building renovation and as a reference for related applications and research.

\section{Methods}

The exterior walls of buildings are usually constructed using composite materials. In Taiwan, the most common material for the decoration of exterior walls of residential buildings is ceramic tiles or wall paint; on the other hand, the decoration of exterior walls for office buildings is more diverse, and materials such as metal-framed curtain walls and glass curtain walls are also used. If the former materials are used, when the surface of the exterior wall flakes or cracks visibly, it has usually already been seriously damaged, and the damaged area may suffer abnormal heat conduction as compared with the undamaged area, causing a surface temperature difference. As infrared thermal imaging can be used to rapidly obtain a comprehensive picture of the entire surface temperature distribution, abnormal areas of the exterior walls can be quickly detected. In addition, if a problem arises from the building's structure or the materials used, this technique can also be used to identify the causes and to help develop appropriate strategies for improvement. Thermal imaging technology uses infrared thermography to measure the infrared intensity of an object (e.g., a building) and its environment, and displays the temperature variation of a scanned scene. The temperature distribution of an object and its environment can be calculated and used for analysis. Comparison of the measured readings of an object with those obtained under normal conditions reveals whether the object is at an abnormal temperature. The images obtained by infrared thermography represent the surface temperature of the measured object, which is mainly affected by internal factors including the characteristics of the surface of the material and the organization of its internal structure. In addition, other environmental factors such as wind speed and moisture can also affect the accuracy of temperature measurement.

\section{Visual detection of the thermal environment of buildings}

Indoor and outdoor areas of abnormal and irregular thermal conductivity often contain thermal bridges. Thermal bridges can often be detected by thermal image analysis. The greater the temperature difference between areas, the more likely it is that a thermal bridge will be found: for instance, if an exterior surface temperature is above $34^{\circ} \mathrm{C}$ and an interior surface temperature is around $25^{\circ} \mathrm{C}$, this temperature difference of around $6-9^{\circ} \mathrm{C}$ is the best condition for 
thermographic analysis. As illustrated in Fig. 1, the use of different construction materials with different heat transfer coefficient $\mathrm{K}$ values causes the formation of a thermal bridge. Thermal imaging can capture enough detail to identify a thermal bridge.

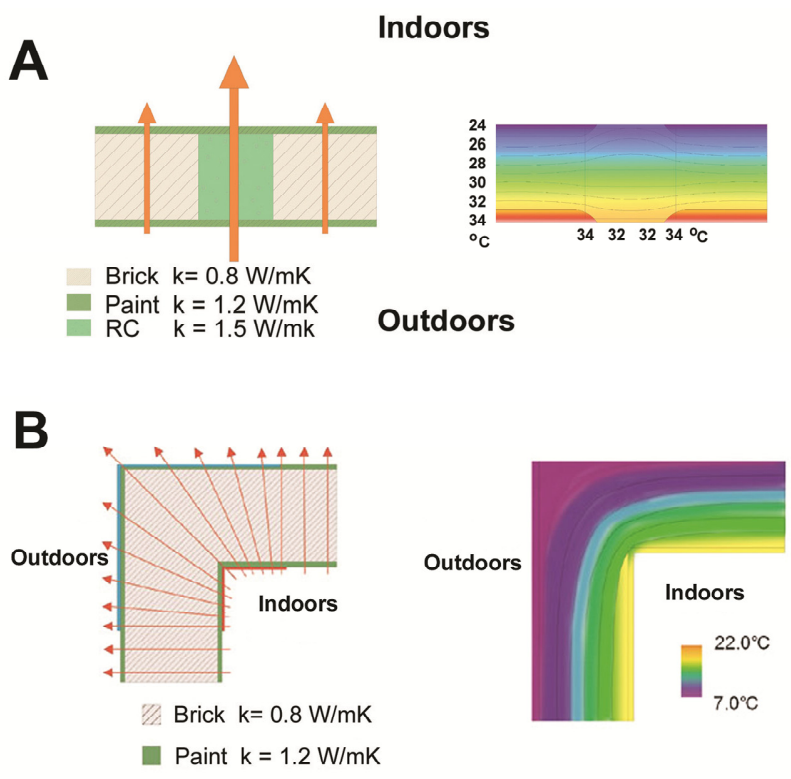

Figure 1: (A) Temperature difference between the interior and exterior surfaces of a wall resulting from the use of different construction materials with different heat transfer coefficients. This results in a thermal bridge. (B) A thermal bridge in a three-dimensional area [5].

In the formation of a thermal bridge in a three-dimensional space, heat conduction occurs from a large (or small) area to a small (or large) area. The corner area therefore maintains a higher temperature by retaining energy (or a lower temperature by losing energy), because it has a larger absorption or emission area. In a three-dimensional space, the corner of the ceiling generally loses or absorbs more energy than other areas (Fig. 1).

\subsection{Visualization of the thermal environment of reinforced concrete (RC) buildings}

This section discusses the analysis of RC frame buildings, especially old buildings, in addition to metal sheet buildings, using infrared thermography. Based on infrared thermographic analysis, the thermal images obtained reveal the reasons for energy wastage in these types of building. As shown in Fig. 2A, in an RC townhouse of over 30 years of age, the tiled and cement exterior walls 
are all of high heat capacity and store solar heat during the day. As they release this solar energy, the temperature of the exterior walls and the outside of the topfloor ceiling can reach above $30^{\circ} \mathrm{C}$. In addition, the temperature of the indoor top-floor ceiling and concrete walls can also easily reach above $30^{\circ} \mathrm{C}$ (Fig. $2 \mathrm{C}-$ $2 \mathrm{~F}$ ), which will greatly increase expenditure on air conditioning and worsen the indoor air quality and environmental comfort level. The temperatures of the outdoor and indoor top-floor ceilings and walls are not significantly different, which indicates that $\mathrm{RC}$ buildings do not resist heat conduction very well. This causes the indoor temperature to be close to that outdoors, resulting in additional energy being used for air-conditioning in the summer and a very cold indoor environment in the winter. In addition, metal sheet rooftop extensions are often seen in old RC buildings in Taiwan, and it can be seen from the thermal image of a metal sheet building with this type of construction shown in Fig. 2B that this leads to an even greater accumulation of heat on the ceiling.
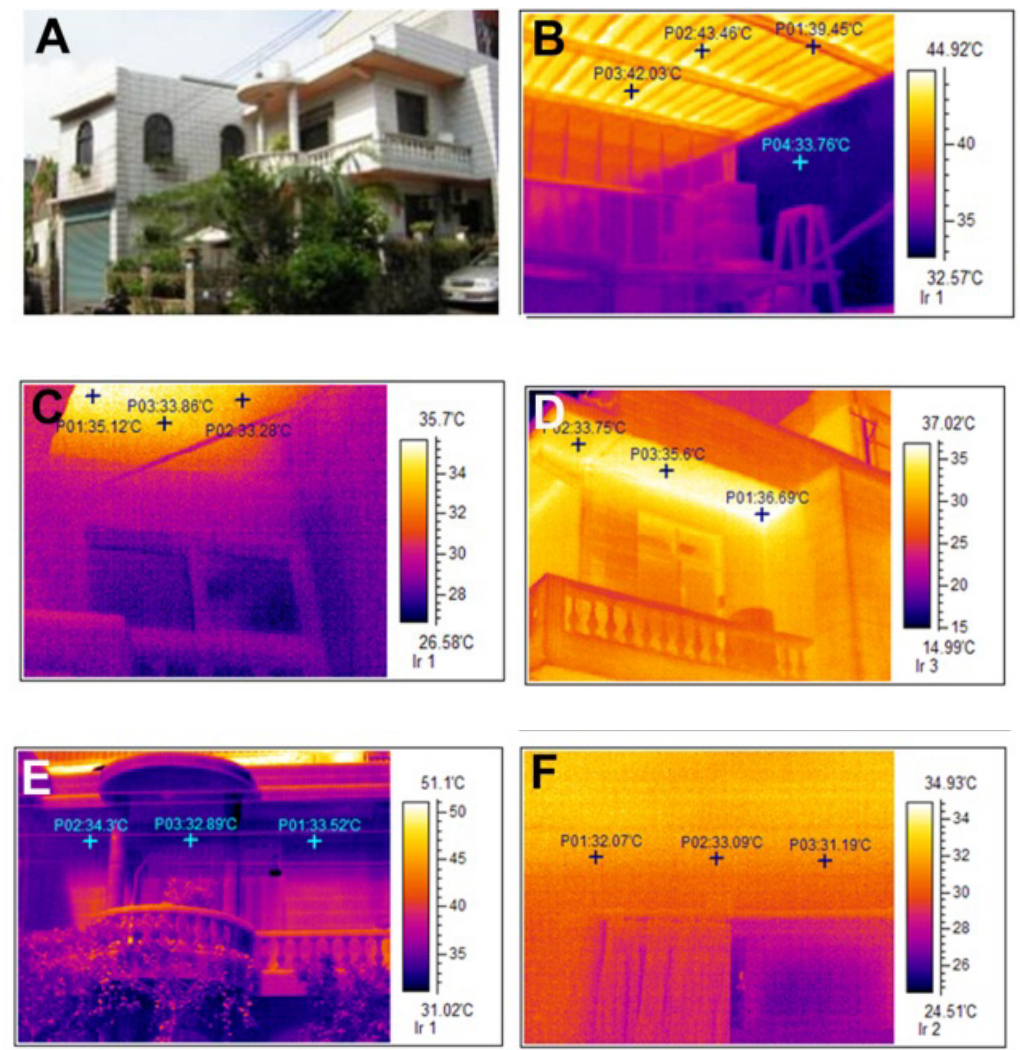

Figure 2: (A) An RC townhouse of over 30 years of age. (B) Metal sheet buildings have the least effective construction, with wasteful consumption of energy. Comparison of the thermal images of the indoor (C) and outdoor (D) ceiling. Comparison of the thermal images of the exterior (E) and interior wall $(\mathrm{F})$. 


\subsection{Visual inspection of the thermal environment of a general RC residential building}

Figure 3 shows the application of thermal imaging to analyze the area in which efflorescence occurs. The variation in color clearly shows the temperature difference over the ceiling and walls, which indicates that moisture is unequally distributed in those areas. However, thermal images of the decorative frame moldings on the ceiling edges are not affected by the ceiling behind, which suggests that infrared thermographic analysis of the decorative materials may not reveal problems, as the characteristics of the construction materials underneath cannot be detected.
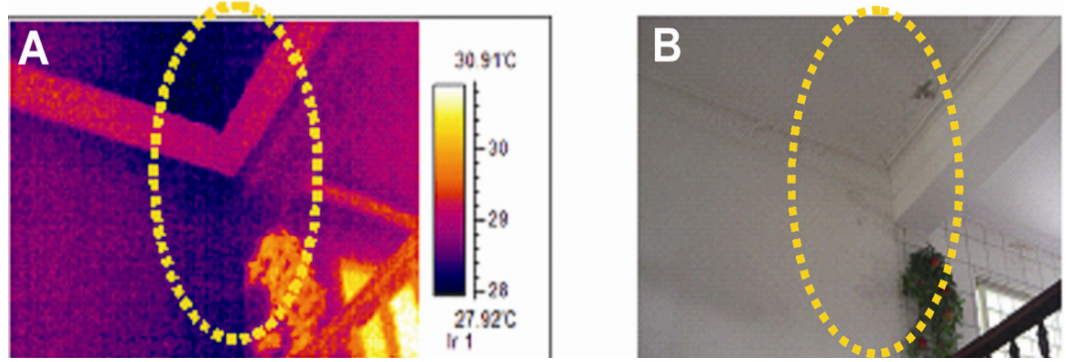

Figure 3: (A) Color variation showing the temperature difference over the top-floor ceiling and wall where efflorescence occurs, as indicated in image (B).
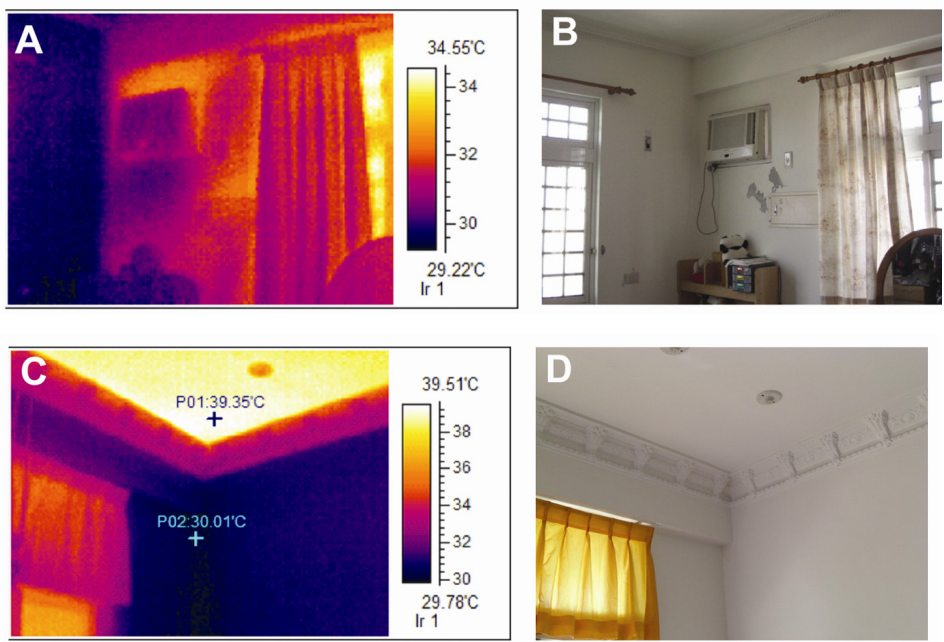

Figure 4: Color variation showing a higher temperature at the gap around the air-conditioner (A and B). Even in mid-autumn, the temperature of the top ceiling can reach nearly $40^{\circ} \mathrm{C}(\mathrm{C}$ and $\mathrm{D})$. 
Vulnerable parts of a building with insulation problems can also be revealed by infrared thermography. If these problematic areas can be identified, suitable thermal break treatment can reduce energy loss to a minimum. Figure 4A and 4B show the temperature of the temperature of a window fitted with an air conditioner: because the gap in the window frame has not been installed with proper insulation material, outdoor heat can be transmitted across (Fig. 4A and $4 \mathrm{~B})$. Figure $4 \mathrm{C}$ and $4 \mathrm{D}$ show that the temperature of the top ceiling reaches up to $40^{\circ} \mathrm{C}$ even in mid-autumn and is about $10^{\circ} \mathrm{C}$ higher than that of other indoor areas. As most of the seasons in the subtropical climate of Taiwan are very hot and humid, the thermal comfort theory proposed by Spagnolo [6] is not applicable in Taiwan.

\subsection{Window frames without thermal treatment}

Figure 5 shows that in a cold season the temperature of indoor window frames is still lower than that of the environment, which indicates that the window frames and glass also act as thermal bridges, losing heat in early spring. In an era in which carbon reduction is being targeted, to achieve efficient energy savings, high-heat-conduction window frames in every house and residential building should be subjected to thermal break treatment in order to reduce the cost of home energy consumption. Thermal break treatment is well worth considering when buildings are due to undergo repair or renovation. In terms of energy policy, the government might need to consider implementing a regulation that recommends such measures as the use of curtain-glass insulation to enhance thermal insulation in certain types of building. In order to reduce heat conduction, double-glazing or low-emissivity (low-E) glass windows can be employed to reduce heat flow between the indoor and outdoor environment.
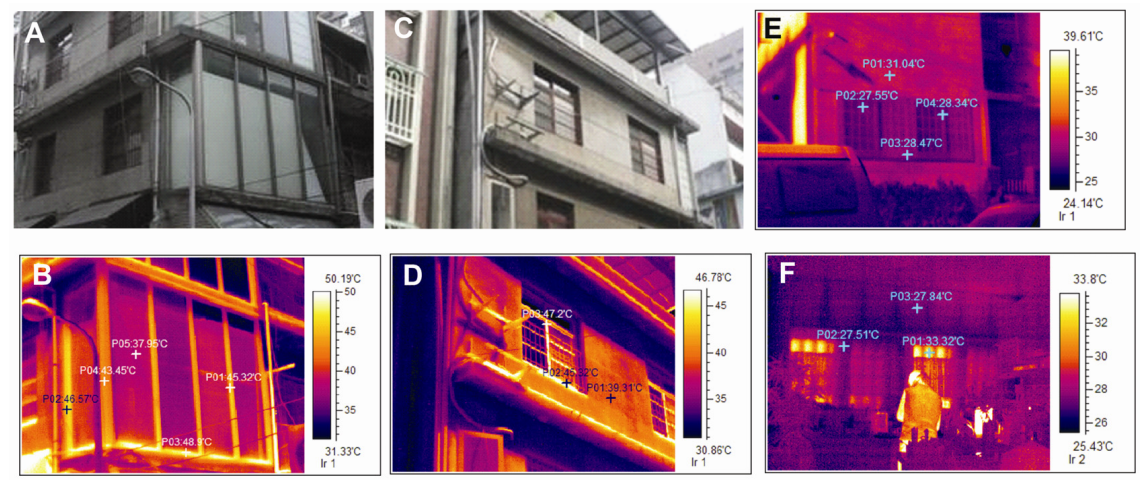

Figure 5: Thermal image of French windows (A and B); wooden window frames are often used in the construction of old buildings ( $\mathrm{C}$ and D); comparison of the outdoor and indoor thermal images of a window in early spring ( $\mathrm{E}$ and $\mathrm{F})$. 


\subsection{Visual inspection of the thermal environment of buildings with a composite-wall structure}

Composite-wall construction is a method that employs lightweight steel frames and a dry-construction technique, reducing construction time, the use of concrete and the weight of the building structure. Therefore, this type of building employs multi-layers of materials as envelopes. In general, it is difficult to identify the position of the metal structures of RC buildings externally, but it is a simple matter to do so by detecting the temperature difference using infrared thermography in buildings with composite-structure walls (Fig. 6). As this type of building is based on dry-wall construction with composite materials, this efficiently reduces the tasks required to be undertaken during decoration or repair.

\subsection{Visual inspection of the structures of buildings with composite-structure walls}

In a building with composite-structure walls, the supporting structure of the kitchen outer wall shown in Fig. 6C can be clearly located by infrared thermography (Fig. 6A and 6B; winter and summer), which will assist workers to avoid the metal structure when installing electrical devices such as switches, plug sockets or lighting fixtures. However, the structural steel is a good conductor and allows heat transmission in both winter and summer, therefore leading to the formation of a thermal bridge. To overcome this problem, a drywall with a low heat transfer coefficient that serves as an insulated panel should be installed to resist heat flow through it. Similarly, the roof support structure of a dry-construction building may also become a thermal bridge (Fig. 6D and 6E; summer and winter), which can be clearly seen using thermal image analysis. Therefore, thermal break treatment of the steel support structure is strongly recommended in order to avoid thermal bridge formation. In addition
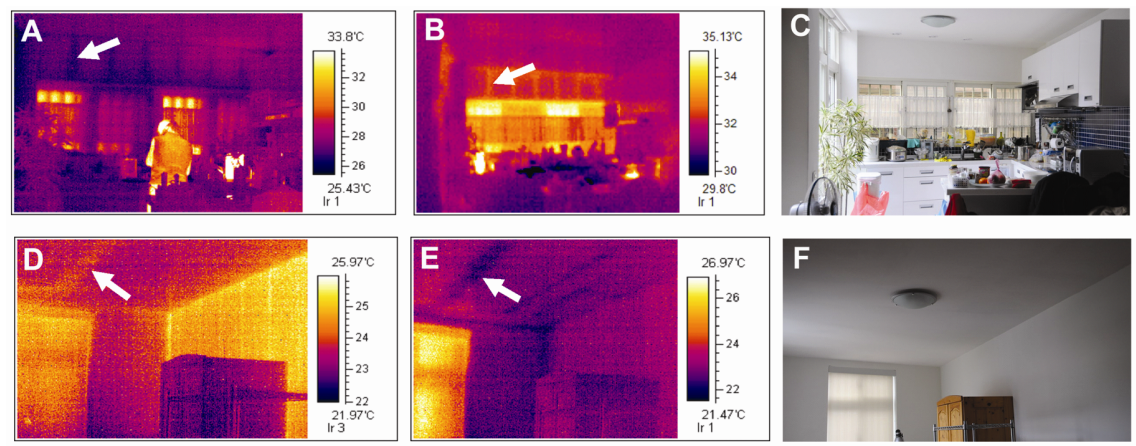

Figure 6: In a dry-construction building, the wall support structure (A and B) and the roof support structure (D and E) becomes a thermal bridge in both summer and winter. (C) and (F) are the RGB images of (A and $\mathrm{B}$ ) and (D and $\mathrm{E})$. 
to use for identifying the problem of a thermal bridge, this technique can also be used to reveal the support structure of a building with composite-construction walls, as shown in Fig. 7.
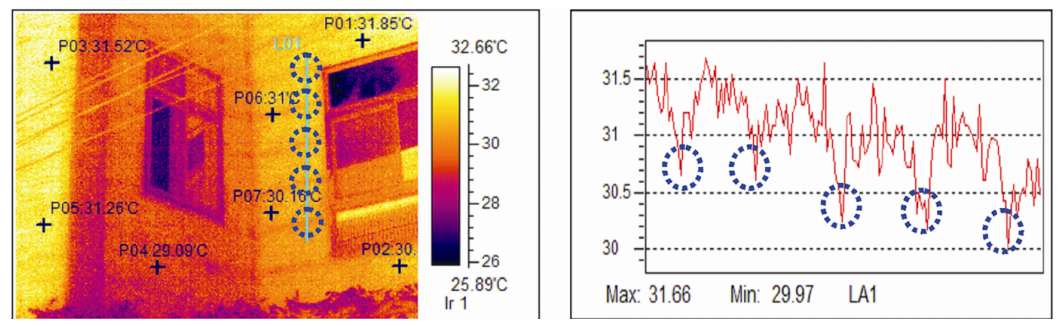

Figure 7: Thermal imaging can reveal the support structure of a building with composite-construction walls (A). The temperature distribution curve (B) along the blue line of the thermal image shows the position of the support materials.

\section{Comparison of the beneficial impacts}

\subsection{Outdoor microclimate of buildings}

Due to rapid urban expansion around the world, in addition to the hard-surface materials (of relatively high thermal conductivity) used in urban areas, most big cities still use impermeable materials for road surfaces. Few cities, Tokyo being one example, have begun to use environment-friendly water-permeable bricks for road surfacing. In Taiwan, the implementation of the use of permeable road surfaces has occurred later than in other countries, but the proportion of impermeable road surfaces laid is decreasing owing to the efforts of the Construction and Planning Agency to promote replacement materials. However, most metropolitan areas still use impermeable surfaces and include a large number of illegally-built metal sheet rooftop extensions, factors that accelerate the heat island effect. The road surfaces and metal sheet roofs of cities in summer reach a high temperature of $40-50^{\circ} \mathrm{C}$, and some of the roofs even reach above $60^{\circ} \mathrm{C}$. Predominantly impermeable surfaces, such as concrete or asphalt pavements, result in alteration of the heat balance in many big cities: these materials retain heat to a great degree and augment the heat island effect, which contributes to worsening of the already poor quality of the urban environment. Murakami et al. [7] and Lin [8] suggest that urban open space can reduce the temperature by planting more trees and even cooling by wind. However, as most of the big cities in Taiwan have a very high density of high-rise buildings, those methods can only have a very limited effect on the improvement of the outdoor micro-climate and temperature comfort [9].

Therefore, as buildings of a composite-wall construction do not contain a large amount of materials of high heat capacity such as concrete, tiles or stones, they do not impact upon the micro-climate to the same degree as do RC 
buildings. In general, the thermal environment around buildings of a compositewall construction is more comfortable than that surrounding RC buildings.

\subsection{Diagnosis and improvement of existing buildings}

An RC building of over 30 years of age is used as an example to examine how the thermal environment of this type of building might be improved (Fig. 8). As described in section 3.1, the thermal images of the top-floor ceiling and outside walls demonstrate problems regarding thermal conductivity. Before renovation, the indoor and outdoor top-floor ceiling, in addition to the interior and exterior walls, were of almost the same temperature in the summer. Renovation was performed by installing composite walls on the existing building surfaces (Fig. 8B), leaving an air space of $1.5 \mathrm{~cm}$ between the newly-installed and the existing walls. Analysis by infrared thermography reveals that the temperature difference between the interior and exterior walls (Fig. 8C and 8D) can reach up to at least $13^{\circ} \mathrm{C}$, which validates the efficiency of composite-wall construction, an improvement that saves greatly on the energy consumption required for indoor air-conditioning.

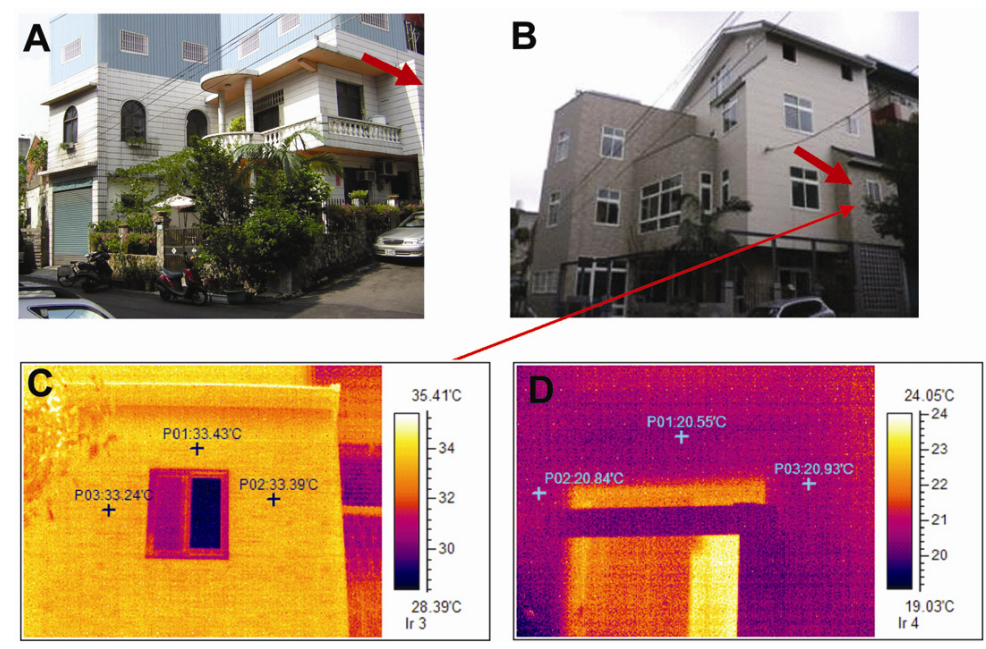

Figure 8: An RC building of over 30 years of age before renovation (A) and after composite-wall installation (B).Thermal image of the exterior wall (C) and the interior wall (D).

In comparison with the heat transfer rates of conventional RC walls (Fig. 9A), the heat transfer rates of composite walls (Fig. 9B) are calculated as below (Table 1):

$$
\mathrm{U}=\frac{1}{\sum R}=\frac{1}{\frac{1}{h_{(e x t)}}+\sum_{i=1}^{n} \frac{d_{i}}{k_{i}}+\frac{1}{h_{(i n t)}}}
$$


$\mathrm{U}=$ heat transfer rate $\left(\mathrm{W} / \mathrm{m}^{2} \mathrm{~K}\right) ; \sum \mathrm{R}=$ total thermal resistance $\left(\frac{m^{2} \cdot K}{W}\right)$;

$\mathrm{H}(\mathrm{ext})=$ heat transfer rate of exterior air film $\left(\mathrm{W} / \mathrm{m}^{2} \mathrm{~K}\right) ; \mathrm{H}(\mathrm{int})=$ heat transfer rate of interior air film $\left(\mathrm{W} / \mathrm{m}^{2} \mathrm{~K}\right)$; di $=$ thickness of material $(\mathrm{m})$; $\mathrm{ki}=$ thermal conductivity of material $(\mathrm{W} / \mathrm{mK})$.

A

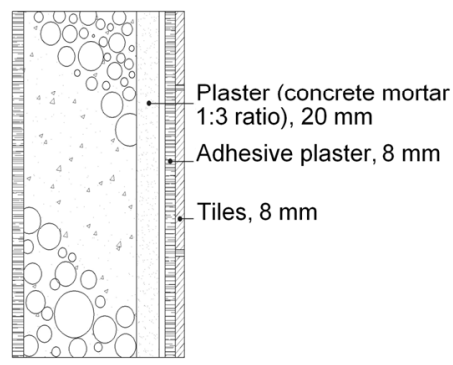

B

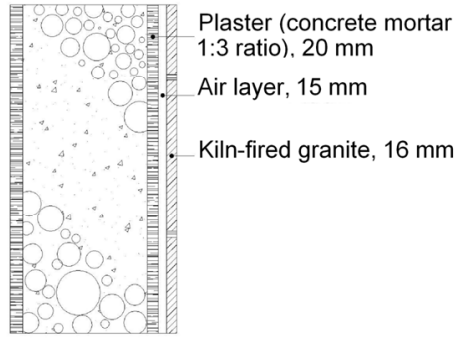

Figure 9: (A) Diagram of the construction of a general tiled wall. (B) Diagram of a kiln-fired granite external wall with an internal air layer.

Table 1: Thermal properties of materials used in the construction of RC buildings.

\begin{tabular}{|c|c|}
\hline Material & Thermal properties \\
\hline $\begin{array}{c}\text { Plaster (concrete } \\
\text { mortar) }\end{array}$ & $\mathrm{k}=1.2 \mathrm{~W} / \mathrm{mK}$ \\
\hline Concrete & $\mathrm{k}=1.4 \mathrm{~W} / \mathrm{mK}$ \\
\hline Kiln-fired granite & $\mathrm{k}=0.37 \mathrm{~W} / \mathrm{mK}$ \\
\hline Tiles & $\mathrm{k}=1.3 \mathrm{~W} / \mathrm{mK}$ \\
\hline Air layer & $\mathrm{R}=0.19 \mathrm{~m}^{2} \mathrm{~K} / \mathrm{W}$ \\
\hline Outdoor air film & $\mathrm{H}_{\text {(int) }}=20 \mathrm{~W} / \mathrm{m}^{2} \mathrm{~K}$ \\
\hline Indoor air film & $\mathrm{H}_{\text {(out) }}=10 \mathrm{~W} / \mathrm{m}^{2} \mathrm{~K}$ \\
\hline
\end{tabular}

(1) Calculation of the individual thermal resistance of each layer of material used in tiled exterior walls, as shown in Fig. 9A (the $\mathrm{K}$ value of concrete mortar is used to represent the binding layer material of the tiles):

Total thermal resistance $\quad \sum \mathrm{R}=0.34\left(\frac{\mathrm{m}^{2} \cdot K}{W}\right)$

$$
\mathrm{U}=\frac{1}{\sum R}=\frac{1}{0.34}=2.94 \mathrm{~W} / \mathrm{m}^{2} \mathrm{~K}
$$


(compliant with the Technology Standards for Energy Saving in Taiwan, section 45-5: The average heat transmission rate should be lower than $3.5 \mathrm{~W} / \mathrm{m}^{2} \mathrm{~K}$ for the outside opaque walls of residential buildings.)

(2) Calculation of the thermal resistance of each layer of material used in composite walls, as shown in Fig. 9B:

Total thermal resistance $\quad \sum \mathrm{R}=0.543\left(\frac{m^{2} \cdot K}{W}\right)$

$$
\mathrm{U}=\frac{1}{\sum R}=\frac{1}{0.543}=1.842 \mathrm{~W} / \mathrm{m}^{2} \mathrm{~K}
$$

The above-calculated heat transmission rates, or $U$ values, indicate that the majority of the heat flow is impeded externally in composite-wall constructions, and therefore the $\mathrm{U}$ value is only $60 \%$ that of conventional tiled $\mathrm{RC}$ walls. This proves that a composite-wall construction can efficiently reduce energy consumption.

\section{Conclusion}

In terms of the entire living environment, architectural constructions must meet some basic requirements in order to ensure the safety, comfort and convenience of the occupants. In addition to concerns regarding the environment and awareness of sustainability, health, ecology, energy-efficiency and minimization of pollution should also be taken into consideration. Therefore, buildings that possess ecological, energy-efficient, pollution-reducing and healthy features are what society expects in the 21 st century. This study investigates and compares the differences between and benefits of composite-wall and conventional RC construction. The findings of this study can be used to propose solutions to improve energy consumption in $\mathrm{RC}$ buildings during renovation and repair. For countries with a hot and humid climate, the benefits of composite-wall construction and methods for renovation and improvement are summarized below (Table 2):

1. "Cladding renovation" is more effective than "facade renovation" in conventional RC buildings.

2. In cladding renovation of an old house, a ventilated air layer is necessary to improve the thermal insulation.

3. Composite-wall construction is a better model as it has a better insulation effect.

4. Materials used to construct multi-layer composite walls should have the characteristic of a high insulation effect: high-insulation materials such as calcium silicate boards, hygroscopic boards, glass wool, and cement and mineral fiberboards should be used, which have U values below $2.5 \mathrm{~W} / \mathrm{m}^{2} \mathrm{~K}$.

5. Exterior walls should be constructed from light-colored materials with a low solar radiation absorption rate.

6. Increasing the thickness of the envelope structure or introducing an air layer will increase the heat capacity and extend the time lag. 
Table 2: Comparison of the advantages and disadvantages of conventional RC buildings and composite-wall buildings.

\begin{tabular}{|c|c|c|c|}
\hline Effects & Conventional RC & Composite-wall & Note \\
\hline Construction duration & Long & Short & \\
\hline Cost & $\begin{array}{l}\text { Low }(\$ 330- \\
\left.520 / \mathrm{m}^{2}\right)\end{array}$ & $\begin{array}{l}\operatorname{High}(\$ 660- \\
\left.710 / \mathrm{m}^{2}\right)\end{array}$ & $\begin{array}{c}\text { In the long term, composite-wall } \\
\text { construction is more economical, as } \\
\text { the added value is higher. }\end{array}$ \\
\hline $\begin{array}{c}\text { Efflorescence } \\
\text { development }\end{array}$ & Often & None & \\
\hline $\begin{array}{c}\text { Indoor temperature and } \\
\text { humidity }\end{array}$ & High & Comfortable & \\
\hline Anti-seismic capability & Poor & Good & \\
\hline $\begin{array}{l}\text { Ceiling and wall cracks, } \\
\text { water seepage }\end{array}$ & Often & No & \\
\hline Environmental benefits & Poor & Good & \\
\hline $\begin{array}{l}\text { Utility pipeline } \\
\text { maintenance }\end{array}$ & Difficult & Easy & \\
\hline Water hammer & No & Yes & $\begin{array}{l}\text { This problem can be solved by adding } \\
\text { an adaptor to the joint of the pipeline. }\end{array}$ \\
\hline $\begin{array}{l}\text { Glass surface } \\
\text { condensation }\end{array}$ & Mild & Yes & $\begin{array}{l}\text { RC buildings are poorly isolated, the } \\
\text { indoor and outdoor temperature } \\
\text { difference is small. Condensation on } \\
\text { glass surfaces is not often seen. This } \\
\text { problem can be alleviated in } \\
\text { composite-wall buildings by } \\
\text { installing double-glazing. }\end{array}$ \\
\hline
\end{tabular}

7. Installation of insulation layers, such as an air layer or a thermal-insulating material, in an exterior wall or a high-temperature surface results in better thermal insulation.

8. Composite-wall dry-construction can reduce the potential for efflorescence development; however, steel structures require thermal break treatment to avoid thermal bridge formation.

9. For aluminum extrusion window frames, the insertion of material with a low thermal conductivity into frames can avoid thermal bridging. Window glass should be double-glazed or low-emissivity (low-E) glass.

10. In consideration of geographical factors affecting sub-tropical countries such as Taiwan, curtain-wall construction is not suitable for building envelopes. However, if some curtain-wall construction is necessary, double-glazing or low-E glass should be used, and window frames also require thermal break treatment.

11. Top-floor ceilings can be designed as a dual-layer ceiling (with a space between the layers) to improve insulation by blocking heat transfer; the addition of a roof garden is also beneficial.

12. Thermal bridges may cause damage to the structure of a building.

13. Thermal imaging is useful to identify the location of thermal bridges. 
14. In parts of a building that often become thermal bridges, some design modifications can be implemented to avoid this outcome.

15. Proper installation of thermal breaks in building envelopes can significantly reduce the cost of energy consumption.

\section{References}

[1] Sun, H., Lauriat, G. \& Nicolas, X. Natural convection and wall condensation or evaporation in humid air-filled cavities subjected to wall temperature variations, International Journal of Thermal Sciences50, pp. 663-679, 2011.

[2] Balaras, C.A. \& Argiriou, A.A. Infrared thermography for building diagnostics. Energy and Buildings, 34, pp. 171-183, 2002.

[3] Haack, A., Schreyer, J. \& Jackel, G. State-of-the-art of Non-destructive Testing Methods for Determining the State of a Tunnel Lining. Tunnelling and Linderground Space Technology, 10(4), pp. 413-431, 1995.

[4] Sakagami, T. \& Kubo, S. Development of a new non-destructive testing technique for quantitative evaluations of delamination defects in concrete structures based on phase delay measurement using lock-in thermography. Infrared Physics\& Technology, 43, pp. 311-316, 2002.

[5] Fouad. A. N. \& Richter, T. LeitfadenThermografieimbauwesen, Fraunhofer IRB Verlag, Stuttgart, Germany, 2007.

[6] Spagnolo J. A field study of thermal comfort in outdoor and semi-outdoor environments in subtropical Sydney Australia. Building and Environment, 38, pp. 721-738, 2003.

[7] Murakami, S., Ooka, R., Mochida, A., Yoshida S. \& Kim S. CFD analysis of wind climate from human to urban scale. Journal of Wind Engineering and Industrial Aerodynamics, 81, pp. 57-81, 1999.

[8] Lin, T.P. Thermal perception, adaptation and attendance in a public square in hot and humid regions, Building and Environment 44, pp. 2017-2026, 2009.

[9] Nikolopoulou M. \& Steemers K. Thermal comfort and psychological adaptation as a guide for designing urban spaces, Energy and Buildings 35, pp. 95-101, 2003. 